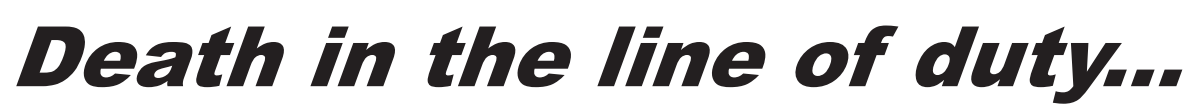

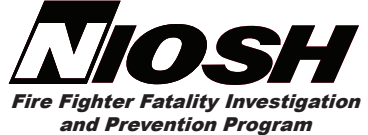

A summary of a NIOSH fire fighter fatality investigation

December, 2014

\section{Firefighter Suffers Fatal Heart Attack While Providing Emergency Medical Services - Washington}

\section{Executive Summary}

On May 14, 2013 at 0700 hours, a 59-year-old male career firefighter (FF) began his 24-hour shift on Ladder 2 (L-2). At 0917 hours L-2 was dispatched to its second medical call of the morning and arrived on scene at 0922 hours. The FF carried two bags of medical equipment up to the second floor and down a long hallway (about 225 feet) to the patient's apartment. The medical bags weighed approximately 25 to 35 pounds each. As the FF positioned the patient's airway, the FF stated he did not feel well. The FF continued to assist the patient, who weighed between 300 and 400 pounds, by lifting him from his motorized wheelchair to the floor. After struggling to get the wheelchair out of the room to give the paramedics room to work, the FF stated he was not doing well (0959 hours). L-2's Driver asked one of the paramedics to evaluate the FF and requested a second ambulance from dispatch. Minutes later, the FF had a cardiac arrest.

Advanced life support (ALS) and cardiopulmonary resuscitation (CPR) were immediately initiated. The FF was loaded into the ambulance at 1004 hours and arrived at the emergency department (ED) at 1008 hours with CPR and ALS in progress. After receiving an oral aspirin on scene and intravenous antithrombus medication in the ED, he was taken emergently to the cardiac catheterization lab where a thrombus in his left main coronary artery confirmed the diagnosis of an acute heart attack. Despite the successful opening of the left main and left anterior descending coronary arteries, the FF died in the cath lab. Both the death certificate and post-mortem examination report were completed by the County Medical Examiners Office which listed "ischemic heart disease" as the cause of death. Given the FF's undiagnosed underlying coronary heart disease (CHD), the National Institute for Occupational Safety and Health (NIOSH) investigator concluded that the alarm response and the physical exertion associated with carrying the medical equipment and moving the patient and his wheelchair triggered a heart attack resulting in the FF's sudden cardiac death.

NIOSH offers the following recommendations to reduce the risk of heart attacks and sudden cardiac arrest among fire fighters at this and other fire departments (FD) across the country.

Require preplacement and annual medical evaluations to identify fire fighters with $\mathrm{CHD}$ risk factors.

Perform symptom-limiting exercise stress tests (ESTs) on firefighters at increased risk for CHD and sudden cardiac events.

Ensure that fire fighters are cleared for return to duty by a physician knowledgeable about the physical demands of fire fighting, the personal protective equipment used by fire fighters, and the components of National Fire Protection Association (NFPA) 1582.

Phase in a mandatory comprehensive wellness and fitness program for fire fighters. 


\section{Firefighter Suffers Fatal Heart Attack While Providing Emergency \\ Medical Services - Washington}

The National Institute for Occupational Safety and Health (NIOSH), an institute within the Centers for Disease Control and Prevention (CDC), is the federal agency responsible for conducting research and making recommendations for the prevention of work-related injury and illness. In 1998, Congress appropriated funds to NIOSH to conduct a fire fighter initiative that resulted in the NIOSH "Fire Fighter Fatality Investigation and Prevention Program" which examines line-of-duty-deaths or on duty deaths of fire fighters to assist fire departments, fire fighters, the fire service and others to prevent similar fire fighter deaths in the future. The agency does not enforce compliance with State or Federal occupational safety and health standards and does not determine fault or assign blame. Participation of fire departments and individuals in NIOSH investigations is voluntary. Under its program, NIOSH investigators interview persons with knowledge of the incident who agree to be interviewed and review available records to develop a description of the conditions and circumstances leading to the death(s). Interviewees are not asked to sign sworn statements and interviews are not recorded. The agency's reports do not name the victim, the fire department or those interviewed. The NIOSH report's summary of the conditions and circumstances surrounding the fatality is intended to provide context to the agency's recommendations and is not intended to be definitive for purposes of determining any claim or benefit. For further information, visit the program website at www.cdc.gov/niosh/fire or call toll free 1-800-CDC-INFO (1-800-232-4636). 


\section{Firefighter Suffers Fatal Heart Attack While Providing Emergency \\ Medical Services - Washington}

\section{Executive Summary (cont.)}

The following recommendations would not have prevented the FF's death, but NIOSH investigators include them to address general safety and health issues.

Develop and conduct annual physical performance (physical ability) evaluations for all members.

Ensure staffing levels consistent with NFPA 1710.

Discontinue routine screening chest $x$-rays for candidates, unless clinically indicated.

\section{Discontinue routine screening lumbar sacral} spine $x$-rays for candidates, unless clinically indicated.

\section{Introduction \& Methods}

On May 14, 2013, a 59-year-old male career FF suffered a fatal heart attack while providing emergency medical services. NIOSH was notified of this fatality on May 15, 2013, by the U.S. Fire Administration. NIOSH contacted the affected FD on May 16, 2013 to obtain additional information, and again on July 10, 2014 to schedule the investigation. On September 3-5, 2014, an investigator from the NIOSH Fire Fighter Fatality Investigation Team conducted an on-site investigation of the incident.
During the investigation, the NIOSH investigator interviewed the following people:

- Fire Chief

- Deputy and Assistant Chief of Operations

- Local Union Officers

- Crewmembers working with the FF during the incident

- Paramedics involved in resuscitation efforts

The NIOSH investigator reviewed the following documents in preparing this report:

- Dispatch logs

- Ambulance report

- ED and cath lab report

- Death certificate

- Autopsy report

- FD statements regarding the incident

\section{Investigative Results}

Incident. On May 14, 2013 at 0700 hours, a 59-year-old male career FF began his 24-hour shift on L-2. During the first hour of the shift, the FF and his crew did their usual morning equipment checks, apparatus checks, and paperwork. At 0842 hours, L-2 was dispatched to a medical call involving a patient having a stroke. The FF was wearing his station uniform and carried L-2's medical equipment to the patient's apartment on the first floor. The FF helped the Medic unit (M-2) evaluate and treat the patient. M-2 transported the patient to the ED while L-2 returned to quarters at 0913 hours. During this medical call the FF expressed no symptoms and showed no signs of distress.

The FD received a second medical call at 0917 hours. Engine 7 was dispatched and, anticipating 


\section{Firefighter Suffers Fatal Heart Attack While Providing Emergency \\ Medical Services - Washington}

\section{Investigative Results (cont.)}

the need for CPR, requested medical assistance from L-2 at 0918 hours. L-2 arrived on scene at 0922 hours and the FF carried two bags of medical equipment up the stairs to the second floor and down a long hallway (approximately $225 \mathrm{feet}$ ) to the patient's apartment. The medical bags weighed 25 to 35 pounds each. As the FF positioned the patient's airway, the Driver of L-2 noted that the FF's was flushed and sweating heavily. The FF stated he did not feel well and was advised by the Driver to take it easy.

As the patient's condition deteriorated, the FF assisted the semi-conscious patient weighing between 300 to 400 pounds from his wheelchair to the floor as the paramedics (M-4) initiated treatment. The FF then struggled to lift and move the motorized wheelchair out of the room to give the paramedics room to work. After getting the wheelchair out of the way, L-2's Driver noted the FF was pale and sweating very heavily. The FF stated he was not doing well (0959 hours), and the Driver asked one of the paramedics from M-4 to evaluate the FF as he requested a second ambulance (M-2) from dispatch.

The paramedic gave the FF oxygen via a nonrebreather mask and was evaluating the FF when the FF seemed to have seizure-like movements and slid onto the floor. Approximately 30 seconds later, the FF lost his pulse and CPR was begun. A cardiac monitor detected a shockable rhythm and a shock was delivered resulting in the brief return of the FF's pulse. The FF was hoisted onto a backboard and carried down the hallway and stairs when his pulse was lost again and CPR was reinitiated. He was loaded into the ambulance (M-2) which departed the scene at 1004 hours.
Enroute to the ED, the FF was intubated with proper tube placement ensured by visualization of the vocal cords, good breath sounds, chest raising with inspiration, and capnography [Neumar et al. 2010]. An intravenous line was placed and cardiac resuscitation medications were administered followed by several defibrillation attempts without a change in the FF's clinical status. The FF arrived at the ED at 1008 hours with CPR and ALS in progress.

The working diagnosis in the ED was either a heart attack or a pulmonary embolus. An electrocardiogram showed changes consistent with an acute heart attack. The FF was given peripheral intravenous tissue plasminogen activator. A cardiac ultrasound showed severe global hypokinesis of the left ventricle with an ejection fraction of 5\% (cardiogenic shock). The FF was taken emergently to the cardiac catheterization lab where a balloon pump was inserted to maintain his blood pressure. Angiography revealed a thrombus in his left main coronary artery that was successfully opened by a combination of thrombolytic agents, aspiration thrombectomy, and percutaneous transluminal coronary angioplasty. Despite the success of opening the FF's blocked coronary arteries, he remained in cardiogenic shock requiring CPR and a temporary pacemaker. After 37 minutes of CPR and ALS in the catheterization lab, the FF was pronounced dead (1141 hour), and resuscitation efforts were stopped.

Medical Findings. Both the death certificate and post-mortem examination report were completed by the County Medical Examiners Office which listed "ischemic heart disease" as the cause of death. The post-mortem examination found an enlarged heart, left ventricular hypertrophy, and 


\section{Firefighter Suffers Fatal Heart Attack While Providing Emergency \\ Medical Services - Washington}

\section{Investigative Results (cont.)}

moderate $(30 \%$ to $80 \%)$ atherosclerotic blockages in multiple coronary arteries (see Appendix A for further details). The post-mortem examination noted the lack of coronary artery thrombus due to its removal during procedures performed in the cardiac catheterization lab.

The FF had no known medical conditions and rarely sought medical care. The FF did not smoke and exercised regularly, however, due to his lack of medical care, it is unclear if he had any of the remaining CHD risk factors: hypertension, diabetes mellitus, high blood cholesterol. The FF participated in the FD's voluntary fitness program by exercising on-duty for an hour with his company. He was an avid outdoorsman, and frequently hiked and ran. Approximately 2 weeks before his death, the FF climbed a 5,944 foot peak without difficultly. He never reported any symptoms or signs suggesting a heart problem. The post-mortem examination listed the FF as 6 feet tall and weighing 235 pounds for a body mass index of 31.9 [CDC 2014].

\section{Description of the Fire Department}

The FD consists of 357 commissioned personnel with 15 fire stations serving a population of 218,000 residents in a geographic area of 75 square miles.

Hiring/Training. The FD requires all fire fighter candidates to complete an application and take a written test. Candidates are banded by their written test scores and then must pass a preliminary background check. A physical ability test is administered and passing candidates are interviewed by FD officials. A final background check is conducted before a position is offered pending the result of the pre-employment/preplacement medical evaluation. Once the candidate is medically cleared, he/she is hired as a recruit. The recruit must then pass the 13-week FD Fire Fighter I training, after which he/she becomes a probationary employee. Over the next 9 months the probationary employee spends 3 months on an Engine crew, 3 months on a Ladder crew, and 3 months roving between other assignments before becoming a member of the FD. At the end of this 1 year period, the new member is qualified as a Fire Fighter I, Fire Fighter II, Emergency Medical Technician, and HazMat operations. The FF was hired by the FD in 1999. In addition to the qualifications listed, he was certified in HazMat Operations and as a Technical Rescue Technician/ Instructor.

Pre-placement Medical Evaluations. The FD requires a pre-placement medical evaluation for all fire fighter candidates. The pre-placement evaluation includes the following items:

- A complete medical history and questionnaire

- Height, weight, and vital signs

- Physical examination

- Vision test (acuity and peripheral fields)

- Hearing test (audiometry)

- Spirometry (lung function tests)

- Blood tests: Complete blood count, chemistry profile which includes cholesterol and triglyceride measurement

- Urinalysis

- Urine drug test

- Resting electrocardiogram

- Exercise stress test (symptom limiting using the Bruce protocol)

- Chest X-ray

- Lumbar/sacral spine X-rays 


\section{Firefighter Suffers Fatal Heart Attack While Providing Emergency \\ Medical Services - Washington}

\section{Description of the FD (cont.)}

The FF passed his pre-placement medical examination in 1999 although these records were not available to NIOSH investigators at the time of this report.

Periodic Medical Evaluations. A comprehensive annual medical examination is required only for fire fighters serving as HazMat technicians. The FD encourages members to have annual medical evaluations from their personal physicians, but the FD does not require or use this information for medical fitness-for-duty decisions. Since the FF did not have a personal physician and was certified in HazMat operations (not technician), he did not have periodic medical evaluations.

Respirators, Return to Work, and Fitness/ Wellness Programs. Annual respirator fit tests are required by the FD. Medical clearance to wear a respirator is required when the fire fighter joins the FD. Fire fighters who miss three or more shifts are required to have a physician's clearance for "return to work." For non-occupational injuries or illnesses, evaluation for clearance would be performed by the FF's personal physician. For work-related injuries or illnesses, evaluation for clearance would be performed by the municipality's physician. The FD has a voluntary fitness program with 1 hour of "in-service" exercise encouraged each shift. Exercise equipment is available in all fire stations.

\section{Discussion}

Atherosclerotic Coronary Heart Disease. The most common risk factor for cardiac arrest and sudden cardiac death is CHD, defined as the buildup of atherosclerotic plaque in the coronary arteries [AHA 2014]. Risk factors for CHD include three non-modifiable factors (age older than 45, male gender, and family history of CHD) and six modifiable factors (diabetes mellitus, smoking, hypertension, high blood cholesterol, obesity, and physical inactivity [AHA 2014; National Cholesterol Education Program 2002]. Although the FF did not smoke and exercised regularly, it is unknown if he had any of the other modifiable CHD risk factors.

The narrowing of the coronary arteries by atherosclerotic plaques occurs over many years, typically decades [Libby 2013]. However, the growth of these plaques probably occurs in a nonlinear, often abrupt fashion. Most heart attacks occur when a vulnerable plaque ruptures, causing a blood clot to form and occlude a coronary artery [Libby 2013]. Establishing a recent (acute) heart attack requires one or more of the following: characteristic electrocardiogram changes, elevated cardiac enzymes, or coronary artery thrombus. In this FF's case, a thrombus was found during the cardiac catheterization confirming an acute heart attack (myocardial infarction).

Physiological Stress. Firefighting is widely acknowledged to be physically demanding. Firefighting activities require fire fighters to work at near maximal heart rates for long periods. An increase in heart rate typically occurs in response to the initial alarm and persists throughout the course of fire suppression activities [Barnard and Duncan 1975; Lemon and Hermiston 1977; Manning and Griggs 1983; Smith et al. 2001]. The 


\section{Firefighter Suffers Fatal Heart Attack While Providing Emergency \\ Medical Services - Washington}

\section{Discussion (cont.)}

FF responded to an alarm for emergency medical services. He climbed a flight of stairs with at least 50 pounds of medical gear and assisted with lifting and moving a 300 to 400 pound patient and his motorized wheelchair. This would have been physically demanding and moderately strenuous [Ainsworth et al. 2011].

\section{Strenuous Exertion and Sudden Cardiac}

Death. Epidemiologic studies in the general population have found that heavy physical exertion can trigger a heart attack and/or sudden cardiac death [Tofler et al. 1992; Mittleman et al. 1993; Willich et al. 1993; Albert et al. 2000]. Epidemiologic studies among fire fighters have shown that fire suppression, training, alarm response, or strenuous physical activity on the job, in the preceding 12 hours, increases the risk for a sudden cardiac event [Kales et al. 2003; Hales et al. 2007; Kales et al. 2007]. NIOSH investigators conclude the FF's sudden cardiac death was the result of a fatal heart attack probably due to a combination of his undiagnosed heart disease, the alarm response, and the moderately strenuous work associated with climbing a flight of stairs with equipment and moving a heavy patient and his wheelchair.

\section{Occupational Medical Standards for Struc-} tural Fire Fighters. To reduce the risk of sudden cardiac arrest or other incapacitating medical conditions among fire fighters, the NFPA developed NFPA 1582, Standard on Comprehensive Occupational Medical Program for FDs [NFPA 2013a]. This voluntary industry standard provides the components of a preplacement and annual medical evaluation. One of the components of the annual medical evaluation includes an assessment of CHD risk factors. The presence of one or more $\mathrm{CHD}$ risk factors increases the risk of $\mathrm{CHD}$ and sudden cardiac death [NHLBI 2013; AHA 2014]. Thus, NFPA 1582, as well as other organizations, recommends ESTs for individuals with CHD risk factors. The following paragraphs outline the positions of these various organizations on the use of ESTs to screen for occult CHD.

NFPA 1582 recommends an EST with or without imaging be performed "when clinically indicated by history or symptoms" and refers the reader to its Appendix A [NFPA 2013]. Items in Appendix $A$ are not standard requirements, but are provided for "informational purposes only." Appendix A recommends using submaximal $(85 \%$ of predicted maximal heart rate) stress tests as a screening tool to evaluate a fire fighter's aerobic capacity. Cardiology evaluation with a symptom-limiting stress test and imaging studies should be used for fire fighters with the following conditions:

- abnormal screening submaximal tests

- cardiac symptoms

- known coronary artery disease (CAD)

- one or more risk factors* for CAD (in men older than 45 and women older than 55)

- fire fighters with a Framingham Risk Score > 10\% [NHLBI 2013]

* Risk factors are defined as hypercholesterolemia (total cholesterol greater than 240 milligrams per deciliter), hypertension (diastolic blood pressure greater than $90 \mathrm{~mm}$ of mercury), smoking, diabetes mellitus, or family history of premature CAD (heart attack or sudden cardiac death in a firstdegree relative less than 60 years old).

The American College of Cardiology/American Heart Association (ACC/AHA) has also published exercise testing guidelines [Gibbons et al. 2002]. 


\section{Firefighter Suffers Fatal Heart Attack While Providing Emergency \\ Medical Services - Washington}

\section{Discussions (cont.)}

The ACC/AHA guideline states the evidence is "less well established" (Class IIb) for the following groups:

- persons with multiple risk factors (defined similarly to those listed by the NFPA)

- asymptomatic men older than 45 years and women older than 55 years:

$\circ$ who are sedentary and plan to start vigorous exercise

- who are involved in occupations in which impairment might jeopardize public safety (e.g., fire fighters)

- who are at high risk for CAD due to other diseases (e.g., peripheral vascular disease and chronic renal failure)

The U.S. Department of Transportation provides guidance for those seeking medical certification for a commercial driver's license. An expert medical panel recommended exercise tolerance tests (stress tests) for asymptomatic "high risk" drivers [Blumenthal et al. 2007]. The panel defines high risk drivers as those with any of the following:

- diabetes mellitus

- peripheral vascular disease

- age 45 and above with multiple risk factors for coronary heart disease

- Framingham risk score predicting a 20\% coronary heart disease event risk over the next 10 years

The U.S. Preventive Services Task Force (USPSTF) does not recommend stress tests for asymptomatic individuals at low risk for CHD events. For individuals at increased risk for CHD events, the USPSTF found "insufficient evidence to recommend for or against routine screening with electrocardiogram, exercise tolerance test, or electron beam computerized tomography scanning ..." Rather, they recommend the diagnosis and treatment of modifiable risk factors (hypertension, high cholesterol, smoking, and diabetes) [USPSTF 2004]. The USPSTF does note that "For people in certain occupations, such as pilots, and heavy equipment operators (for whom sudden incapacitation or sudden death may endanger the safety of others), consideration other than the health benefit to the individual patient may influence the decision to screen for coronary heart disease."

It is unknown if the FF had any modifiable CHD risk factors due to his infrequent use of the health care system. Therefore, it is unclear if an EST was indicated.

\section{Cardiomegaly/Left Ventricular Hypertro-} phy. On autopsy, the FF was found to have left ventricular hypertrophy and an enlarged heart (cardiomegaly). Hypertrophy of the heart's left ventricle is a relatively common finding among individuals with long-standing hypertension, a heart valve problem, or chronic cardiac ischemia (reduced blood supply to the heart muscle) [Siegel 1997]. The FF did not have any valve abnormalities on autopsy; therefore the most likely reason for his left ventricular hypertrophy was either undiagnosed chronic cardiac ischemia or longstanding hypertension. 


\section{Firefighter Suffers Fatal Heart Attack While Providing Emergency Medical Services - Washington}

\section{Recommendations}

NIOSH investigators offer the following recommendations to reduce the risk of on-the-job heart attacks and sudden cardiac arrest among fire fighters.

Recommendation \#1: Require preplacement and annual medical evaluations to identify fire fighters with CHD risk factors.

Guidance regarding the content and frequency of these medical evaluations can be found in NFPA 1582 and in the International Association of Fire Fighters (IAFF)/International Association of Fire Chiefs (IAFC) Fire Service Joint Labor Management Wellness/Fitness Initiative [IAFF, IAFC 2008; NFPA 2013a]. These evaluations are performed to determine fire fighters' medical ability to perform duties without presenting a significant risk to the safety and health of themselves or others.

Recommendation \#2: Perform symptom-limiting ESTs on firefighters at increased risk for CHD and sudden cardiac events.

Firefighters with multiple or severe CHD risk factors, or a high Framingham score, are at increased risk of a sudden cardiac event [NHLBI 2013, AHA 2014]. Currently, the FD does not screen members for CHD risk factors or require exercise stress tests for fire fighters at increased risk for a sudden cardiac event.

Recommendation \#3: Ensure that fire fighters are cleared for return to duty by a physician knowledgeable about the physical demands of fire fighting, the personal protective equipment used by fire fighters, and the various components of NFPA 1582.
According to NFPA 1582, the FD should have an officially designated physician who is responsible for guiding, directing, and advising the members with regard to their health, fitness, and suitability for duty [NFPA 2013a]. The physician should review job descriptions and essential job tasks required for all $\mathrm{FD}$ positions to understand the physiological and psychological demands of fire fighters and the environmental conditions under which they must perform, as well as the personal protective equipment they must wear during various types of emergency operations. The FD currently uses the member's personal physician to initially clear fire fighters who miss work due to a lengthy (more than three shifts) illness. Personal physicians may be unaware of the hazardous and physical demands of structural fire fighting and the guidance provided by NFPA 1582 .

\section{Recommendation \#4: Phase in a mandatory} comprehensive wellness and fitness program for fire fighters.

The FD currently has a voluntary fitness program with 1 hour of "in-service" exercise encouraged each shift. We applaud the FD for acknowledging the importance of fitness to reduce CHD and CHD risk factors, however, mandatory programs have shown the most benefit [Dempsey et al. 2002; Womack et al. 2005; Blevins et al. 2006; Poston et al. 2013]. A study by the Oregon Health and Science University reported a savings of more than $\$ 1$ million for each of four large fire departments implementing the IAFF/IAFC wellness/fitness program compared to four large fire departments not implementing a program. These savings were primarily due to a reduction of occupational injury/illness claims with additional savings expected from reduced future non-occupational healthcare 


\section{Firefighter Suffers Fatal Heart Attack While Providing Emergency Medical Services - Washington}

\section{Recommendations (cont.)}

costs [Kuehl 2007, 2013]. NIOSH recommends a formal, comprehensive, and mandatory wellness/ fitness program to ensure all members receive the benefits of a health promotion program. Guidance for these programs can be found in NFPA 1583, Standard on Health-Related Fitness Programs for Fire Fighters, and the IAFF/IAFC Fire Service Joint Labor Management Wellness/Fitness Initiative, [IAFF, IAFC 2008; NFPA 2008; Schneider 2010].

The following recommendations would not have prevented the FF's death, but NIOSH investigators include them to address general safety and health issues.

Recommendation \#5: Develop and conduct annual physical performance (physical ability) evaluations for all members.

NFPA 1500, Standard on Fire Department Occupational Safety and Health Program recommends that FDs develop the physical performance requirements for fire fighters (paragraph 10.2.1) [NFPA 2013b]. The standard also recommends that FDs qualify/test members to meet these requirements (paragraph 10.2.3). This ensures fire fighters are physically capable of performing the essential job tasks of structural fire fighting.

Recommendation \#6: Provide adequate fire fighter staffing to ensure safe operating conditions.

The FD staffs some of its engines and ladders with three persons. NFPA 1710 requires that fire companies whose primary functions are to perform Engine- or Ladder/Truck-type work be staffed with a minimum of four persons [NFPA 2010]. Understaffing causes those members on-scene to work harder and for longer periods of time. Additionally, it requires the use of extra fire companies in order to meet the demand for manpower. Engine and Ladder Companies should be staffed with four persons at a minimum.

\section{Recommendation \#7: Discontinue routine} screening chest $x$-rays for candidates, unless clinically indicated.

The FD obtains chest $\mathrm{x}$-rays during the pre-employment/pre-placement medical evaluation. Although NFPA 1582 recommends an initial baseline chest $\mathrm{x}$-ray, screening chest x-rays without a clinical indication are not recommended by the OSHA hazardous materials standard (hazardous waste operations and emergency response) [NIOSH 1985; CFR 2012]. Performing unwarranted x-rays exposes members to radiation and is an unnecessary expense for the FD [Tigges et al. 2004].

\section{Recommendation \#8: Discontinue routine screening lumbar-sacral spine $x$-rays for candi- dates, unless clinically indicated.}

The FD performs preplacement screening lumbar spine $\mathrm{x}$-rays. While these $\mathrm{x}$-rays may be useful in evaluating individuals with existing problems, the American College of Radiology, American College of Occupational and Environmental Medicine, and NIOSH investigators have concluded that lumbar spine x-rays have no value as a routine screening measure to determine future risk of back injuries [Present 1974; Lincoln et al. 1979; Gibson 1998]. Screening lumbar spine $\mathrm{X}$-rays are an unnecessary radiation exposure for the individual and an unnecessary expense for the fire department. 


\section{Firefighter Suffers Fatal Heart Attack While Providing Emergency \\ Medical Services - Washington}

\section{References}

AHA [2014]. Understand your risk of heart attack. American Heart Association. [http://www.heart. org/HEARTORG/Conditions/HeartAttack/UnderstandYourRiskofHeartAttack/Understand-YourRisk-of-Heart-Attack_UCM_002040_Article.jsp]. Date accessed: September 2014.

Ainsworth BE, Haskell WL, Herrmann SD, Meckes N, Bassett DR Jr, Tudor-Locke C, Greer JL, Vezina J, Whitt-Glover MC, Leon AS [2011]. Compendium of physical activities: a second update of codes and MET values. Med Sci Sports Exerc 43(8):1575-1581.

Albert CM, Mittleman MA, Chae CU, Lee IM, Hennekens CH, Manson JE [2000]. Triggering of sudden death from cardiac causes by vigorous exertion. N Engl J Med 343(19):1355-1361.

Barnard RJ, Duncan HW [1975]. Heart rate and ECG responses of firefighters. J Occup Med 17(4): 247-250.

Blevins JS, Bounds R, Armstrong E, Coast JR [2006]. Health and fitness programming for fire fighters: does it produce results? Med Sci Sports Exerc 38(5):S454.

Blumenthal RS, Epstein AE, Kerber RE [2007]. Expert panel recommendations. Cardiovascular disease and commercial motor vehicle driver safety. [http://www.mrb.fmcsa.dot.gov/documents/ CVD_Commentary.pdf]. Date accessed: September 2014.

CDC [2014]. Assessing your weight. Centers for Disease Control and Prevention. [http://www.cdc. gov/healthyweight/assessing/index.html]. Date accessed: September 2014.

CFR [2012]. Code of Federal Regulations [29 CFR 1910.120]. OSHA standards interpretation. Medical surveillance requirements for hazmat workers. Washington, DC: U.S. Government Printing Office, Office of the Federal Register. [https:// www.osha.gov/pls/oshaweb/owadisp.show document?p_table $=$ INTERPRETATIONS\&p_ id=28301]. Date accessed: September 2014.

Dempsey WL, Stevens SR, Snell CR [2002]. Changes in physical performance and medical measures following a mandatory firefighter wellness program. Med Sci Sports Exerc 34(5):S258.

Gibbons RJ, Balady GJ, Bricker JT, Chaitman BR, Fletcher GF, Froelicher VF, Mark DB, McCallister BD, Mooss AN, O'Reilly MG, Winters WL Jr., Antman EM, Alpert JS, Faxon DP, Fuster V, Gregoratos G, Hiratzka LF, Jacobs AK, Russell RO, Smith SC Jr. [2002]. ACC/AHA 2002 guideline update for exercise testing: a report of the American College of Cardiology/American Heart Association Task Force on Practice Guidelines. Circulation 106(14):1883-1892.

Hales T, Jackson S, Baldwin T [2007]. NIOSH Alert: Preventing Fire Fighter Fatalities Due to Heart Attacks and Other Sudden Cardiovascular Events. Department of Health and Human Services, Public Health Service, Centers for Disease Control and Prevention, National Institute for Occupational Safety and Health Publication No. 2007-133. [http://www.cdc.gov/niosh/docs/2007133/]. Date Accessed: September 2014. 


\section{Firefighter Suffers Fatal Heart Attack While Providing Emergency \\ Medical Services - Washington}

\section{References (cont.)}

IAFF, IAFC [2008]. The fire service joint labor management wellness/fitness initiative. 3rd ed. Washington, DC: International Association of Fire Fighters, International Association of Fire Chiefs.

Kales SN, Soteriades ES, Christoudias SG, Christiani DC [2003]. Fire fighters and on-duty deaths from coronary heart disease: a case control study. Environ Health 2(1):14.

Kales SN, Soteriades ES, Christophi CA, Chirstiani DC [2007]. Emergency duties and deaths from heart disease among fire fighters in the United States. New Engl J Med 356(12):1207-1215.

Kuehl K [2007]. Economic impact of the wellness fitness initiative. Presentation at the 2007 John P. Redmond Symposium in Chicago, IL on October 23, 2007.

Kuehl KS, Elliot DL, Goldberg L, Moe EL, Perrier E, Smith J [2013]. Economic benefit of the PHLAME wellness programme on firefighter injury. Occup Med 63(3):203-209.

Lemon PWR, Hermiston RT [1977]. The human energy cost of fire fighting. J Occup Med 19:558-565.

Libby P [2013]. Mechanisms of Acute Coronary Syndromes and Their Implications for Therapy. N Engl J Med 368:2004-2013.

Lincoln TA, Kelly FJ, Lushbaugh CC, Milroy WC, Voelz GL, Wollenweber HL [1979]. Guidelines for use of routine $\mathrm{x}$-ray examinations in occupational medicine. Committee report.

J Occup Med 21(7):500-502.
Manning JE, Griggs TR [1983]. Heart rates in fire fighters using light and heavy breathing equipment:

Similar near-maximal exertion in response to multiple work load conditions. J Occup Med. 25(3): 215-218.

Mittleman MA, Maclure M, Tofler GH, Sherwood JB, Goldberg RJ, Muller JE [1993]. Triggering of acute myocardial infarction by heavy physical exertion. $\mathrm{N}$ Engl J Med 329(23):1677-1683.

NFPA [2008]. Standard on health-related fitness programs for fire fighters. Quincy, MA: National Fire Protection Association. NFPA 1583.

NFPA [2010]. NFPA 1710, Standard for the Organization and Deployment of Fire Suppression Operations, Emergency Medical Operations, and Special Operations to the Public by Career Fire Departments. Quincy, MA: National Fire Protection Association.

NFPA [2013a]. Standard on comprehensive occupational medical program for fire departments. Quincy, MA: National Fire Protection Association. NFPA 1582.

NFPA [2013b]. Standard on fire department occupational safety and health program. Quincy, MA: National Fire Protection Association. NFPA 1500.

NHLBI (National Heart, Lung, and Blood Institute) [2013]. Risk assessment tool for estimating your 10-year risk of having a heart attack. [http:// cvdrisk.nhlbi.nih.gov/calculator.asp]. Date accessed: September 2014. 


\section{Firefighter Suffers Fatal Heart Attack While Providing Emergency Medical Services - Washington}

National Cholesterol Education Program [2002]. Third Report of the National Cholesterol Education Program (NCEP) Expert Panel on Detection, Evaluation, and Treatment of High Blood Cholesterol in Adults (Adult treatment Panel III). NIH Publication No. 02-5215. National Institutes of Health, National Heart, Lung, and Blood Institute. Washington: Government Printing Office.

NIOSH [1985]. Occupational safety and health guidance manual for hazardous waste site activi-ties. Cincinnati, OH: U.S. Department of Health and Human Services, Public Health Service, Centers for Disease Control, National Institute for Occupational Safety and Health, DHHS (NIOSH) Publication No. 85-115. [http://www.cdc.gov/niosh/pdfs/85-115-a.pdf]. Date accessed: September 2014.

Neumar RW, Otto CW, Link MS, Kronick SL, Shuster M, Callaway CW, Kudenchuk PJ, Ornato JP, McNally B, Silvers SM, Passman RS, White RD, Hess EP, Tang W, Davis D, Sinz E, Morrison LJ [2010]. Part 8: Adult advanced cardiovascular life support. 2010 American Heart Association Guidelines for cardiopulmonary resuscitation and emergency cardiovascular care. Dallas, TX: Amer ican Heart Association.

Poston WSC, Haddock CK, Jahnke SA, Jitnarin N, Day RS [2013]. An examination of the benefits of health promotion programs for the national fire service. BMC Pub Health 13(1):805-819.

Present AJ [1974]. Radiography of the lower back in pre-employment physical examinations. Conclusions of the ACR/NIOSH Conference, January 11-14, 1973. Radiology 112(1):229-230.

Schneider EL [2010]. Firefighter fitness: a health and wellness guide. New York: Nova Science Publishers.
Siegel RJ [1997]. Myocardial hypertrophy. In: Bloom S, ed. Diagnostic criteria for cardiovascular pathology acquired diseases. Philadelphia, PA: Lippencott-Raven.

Smith DL, Manning TS, Petruzzello SJ [2001]. Effect of strenuous live-drills on cardiovascular and psychological responses of recruit fire fighters. Ergonomics 44(3): 244-254.

Tigges S, Roberts DL, Vydareny KH, Schulman DA [2004]. Routine chest radiography in a primary care setting. Radiol 233(2):575-578.

Tofler GH, Muller JE, Stone PH, Forman S, Solomon RE, Knatterud GL, Braunwald E [1992]. Modifiers of timing and possible triggers of acute myocardial infarction in the Thrombolysis in Myocardial Infarction Phase II (TIMI II) Study Group. J Am Coll Cardiol 20(5):1049-1055.

USPSTF [2004]. U.S. Prevention Services Task Force. Screening for coronary heart disease: Recommendation Statement. Ann Intern Med 140(7):569-572.

Willich SN, Lewis M, Lowel H, Arntz HR, Schubert F, Schroder R [1993]. Physical exertion as a trigger of acute myocardial infarction. $\mathrm{N}$ Engl J Med 329(23):1684-1690.

Womack JW, Humbarger CD, Green JS, Crouse SF [2005]. Coronary artery disease risk factors in firefighters: effectiveness of a one-year voluntary health and wellness program. Med Sci Sports Exerc 37(5):S385. 


\section{Firefighter Suffers Fatal Heart Attack While Providing Emergency \\ Medical Services - Washington}

\section{Investigator Information}

This incident was investigated by the

NIOSH Fire Fighter Fatality Investigation and Prevention Program, Cardiovascular Disease Component located in Cincinnati, Ohio. Thomas Hales led the investigation and authored the report. Dr. Hales is a member of the NFPA Technical Committee on Occupational Safety and Health, and Vice Chair of the Public Safety Medicine Section of the American College of Occupational and Environmental Medicine (ACOEM). 


\section{Firefighter Suffers Fatal Heart Attack While Providing Emergency Medical Services - Washington}

\section{Appendix A}

\section{Autopsy Findings}

- Heart size - enlarged

$\circ$ Heart weight $=500$ grams (expected weight 384 grams) [Silver and Silver 2001]

- Coronary arteries - multifocal calcified atherosclerosis

$\circ$ Left main coronary artery $75 \%$ stenosis

○ Left anterior descending $60 \%$ stenosis proximally and midsegments, $30 \%$ distally

- Circumflex less than $30 \%$ stenosis

- Right coronary artery $30 \%$ stenosis proximally, $80 \%$ midpoint, and $30 \%$ distally

- Myocardium - hypertrophy

- Concentric left ventricular hypertrophy measuring 1.5 centimeter $(\mathrm{cm})$, normal at autopsy is 0.76-0.88 cm [Colucci and Braunwald 1997]

- No evidence or old or new infarct (heart attack), but these changes typically take several days and weeks to become apparent [Siegel 1997].

- Normal heart valves

- No pulmonary thrombus or embolus

- Negative toxicology and illicit drug screens

\section{References}

Colucci WS, Braunwald E [1997]. Pathophysiology of heart failure. In: Braunwald, ed. Heart disease. 5th ed. Philadelphia, PA: W.B. Saunders Company, p. 401.

Siegel RJ [1997]. Myocardial hypertrophy. In: Bloom S, ed. Diagnostic criteria for cardiovascular pathology acquired diseases. Philadelphia, PA: Lippencott-Raven.

Silver MM, Silver MD [2001]. Examination of the heart and of cardiovascular specimens in surgical pathology. In: Silver MD, Gotlieb AI, Schoen FJ, eds. Cardiovascular pathology. 3rd ed. Philadelphia, PA: Churchill Livingstone, pp. 8-9. 